\title{
Evidence of asymptomatic submicroscopic malaria in low transmission areas in Belaga district, Kapit division, Sarawak, Malaysia
}

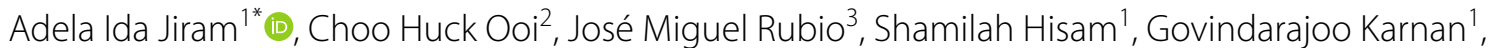
Nurnadiah Mohd Sukor ${ }^{1}$, Mohd Mafie Artic ${ }^{1}$, Nor Parina Ismail ${ }^{1}$ and Nor Wahida Alias ${ }^{1}$

\begin{abstract}
Background: Malaysia has declared its aim to eliminate malaria with a goal of achieving zero local transmission by the year 2020. However, targeting the human reservoir of infection, including those with asymptomatic infection is required to achieve malaria elimination. Diagnosing asymptomatic malaria is not as straightforward due to the obvious lack of clinical manifestations and often subpatent level of parasites. Accurate diagnosis of malaria is important for providing realistic estimates of malaria burden and preventing misinformed interventions. Low levels of parasitaemia acts as silent reservoir of transmission thus remains infectious to susceptible mosquito vectors. Hence, the aim of this study is to investigate the prevalence of asymptomatic submicroscopic malaria (SMM) in the District of Belaga, Sarawak.
\end{abstract}

Methods: In 2013, a total of 1744 dried blood spots (DBS) were obtained from residents of 8 longhouses who appeared healthy. Subsequently, 251 venous blood samples were collected from residents of 2 localities in 2014 based on the highest number of submicroscopic cases from prior findings. Thin and thick blood films were prepared from blood obtained from all participants in this study. Microscopic examination were carried out on all samples and a nested and nested multiplex PCR were performed on samples collected in 2013 and 2014 respectively.

Results: No malaria parasites were detected in all the Giemsa-stained blood films. However, of the 1744 samples, 29 (1.7\%) were positive for Plasmodium vivax by PCR. Additionally, of the 251 samples, the most prevalent mono-infection detected by PCR was Plasmodium falciparum 50 (20\%), followed by P. vivax 39 (16\%), P. knowlesi 9 (4\%), and mixed infections 20 (8\%).

Conclusions: This research findings conclude evidence of Plasmodium by PCR, among samples previously undetectable by routine blood film microscopic examination, in local ethnic minority who are clinically healthy. SMM in Belaga district is attributed not only to $P$. vivax, but also to $P$. falciparum and $P$. knowlesi. In complementing efforts of programme managers, there is a need to increase surveillance for SMM nationwide to estimate the degree of SMM that warrant measures to block new transmission of malaria.

Keywords: Submicroscopic, Malaria, Asymptomatic, Belaga, Sarawak, Low transmission, Plasmodium

\footnotetext{
*Correspondence: adelajiram@gmail.com

1 Parasitology Unit, Infectious Diseases Research Centre, Institute for Medical Research, Ministry of Health Malaysia, Jalan Pahang, 50588 Kuala Lumpur, Malaysia

Full list of author information is available at the end of the article
} 


\section{Background}

Malaysia declared its aim to eliminate malaria with a goal of achieving zero local transmission by the year 2020 . However, malaria continues to be a public health burden especially in the interior parts of the country, which accounts for a considerable number of cases treated at health clinics and admissions to hospitals. Although both Plasmodium vivax and Plasmodium falciparum are prevalent, in recent years, Plasmodium knowlesi has been recognized as the infective agent for an increasing number of cases, especially in Malaysia. In 2017, the country reported a total of 508 cases (local and imported) of the human type of malaria, down substantially from 6141 cases in 2010 [1]. However, up to 88\% (3614/4114) of the country's malaria cases are attributable to $P$. knowlesi, while $P$. vivax and P. falciparum accounts for $7 \%$ and $4 \%$ of total cases, respectively. The remaining $0.7 \%, 0.4 \%$ and $0.1 \%$ accounts for $P$. ovale, $P$. malariae and mixed infections respectively [2]. Sixty-eight percent of total malaria cases are found in Malaysian Borneo, in the states of Sabah and Sarawak. The remaining one-third (32\%) of cases occur in Peninsular Malaysia, in the central, southeastern and northern coastal regions.

Despite the decline in the number of malaria cases in the country, there have been reports of vivax and falciparum malaria cases in low endemic areas especially in the rural settings in Sarawak [2]. Nonetheless, all the human malaria cases are imported. Sarawak recorded a decline in malaria reported cases from 2802 in 2010 to 1442 cases in 2017 with 212 cases of human malaria and 1225 cases of zoonotic malaria where Kapit division registered the most number of malaria cases with 565 (all P. knowlesi). Kapit Division consists of three districts (Kapit, Song and Belaga). Malaysia is home to many isolated indigenous tribal groups that do not generally have the same level of access to health care as the rest of the population. Many indigenous people use traditional remedies before seeking care in a health facility, which can delay treatment. Many of these groups live within the forest or forest-fringe areas, where the vector ecology and transmission patterns of malaria present a unique challenge for vector control management [3].

At all levels of Plasmodium transmission, there are individuals with submicroscopic infection present in the population. The relative proportion of submicroscopic and microscopic infections varies between settings, depending on factors such as age, transmission intensity and immunity. In low transmission settings, submicroscopic infections may represent a significant fraction of infections, but the major determinants of the contribution of submicroscopic infections to malaria transmission are not clear. Submicroscopic infections are prevalent both in "stable" low endemic areas and in those areas experiencing recent reductions in transmission. It has previously been reported that in low transmission settings, the proportion of asymptomatic individuals is less than that in areas of greater transmission severity. Nonetheless, even in low transmission areas the asymptomatic cases make up for $60 \%$ of the infected population.

Despite rarely causing clinical disease, submicroscopic malaria infections can contribute to malaria transmission. Experimental evidence has demonstrated that individuals with submicroscopic infections are capable of infecting mosquitoes; while these individuals may infect fewer mosquitoes than individuals with higher parasite counts, the high numbers of individuals with low-density infections may lead them to contribute substantially to malaria transmission [4]. Understanding the prevalence of these infections and the extent to which they contribute to malaria transmission is critical for designing effective malaria control programmes. Achieving malaria elimination requires targeting the human reservoir of infection, including those with asymptomatic infection. Smear-positive asymptomatic infections detectable by microscopy are an important reservoir because they often persist for months and harbour gametocytes, the parasite stage infectious to mosquitoes. However, many asymptomatic infections are submicroscopic and can only be detected by molecular methods. This was evident in a paper by Jiram et al. [5], which indicates that the use of molecular method is imperative to show evidence of asymptomatic submicroscopic malaria within the Orang Asli (aboriginal) community. In this study, all samples were negative by microscopic examination. The use of molecular biology for the diagnosis of malaria has proved to be highly sensitive for the detection of the parasite, but the equipment required is not widely available in many of the endemic areas and the protocol is more complex and requires highly skilled personnels. The use of the polymerase chain reaction (PCR), however, is extremely useful for decision making in disease control and treatment, for example, for the detection of mixed infections which play a modulatory role in the severity of the symptoms [6-8]. The greatest advantage, however, is that the ultra-sensitive PCR now has ability to detect infections with parasitaemia as low as 22 parasites/ml blood $[9,10]$. As malaria elimination programmes pursue mass screening and treatment of asymptomatic individuals, further research should strive to define the degree to which submicroscopic malaria contributes to the infectious reservoir and, in turn, what diagnostic detection threshold is needed to effectively interrupt transmission. Asymptomatic malaria is prevalent in malaria endemic regions and has become a serious threat as efforts towards eliminating malaria transmission are increasing [11]. 
Data on submicroscopic parasitaemia is needed to better understand disease progression and its impact on targets set in the National Malaria Elimination Programme. Current evidence is insufficient for understanding the contribution of low-density SMM infections to onward transmission to human populations. Intervention trials to directly assess the effect of identifying and treating lowdensity infections are warranted. Presently, limited studies on asymptomatic submicroscopic malaria are carried out in Malaysia. Both parasite and host factors will influence whether infections remain asymptomatic or become symptomatic and potentially life threatening. In order for Malaysia to achieve the national goal of malaria elimination by 2020 , it is important to understand that asymptomatic submicroscopic infection plays an important role in malaria transmission and that interventions to target this parasite reservoir may be needed in both low- and high-transmission areas. Currently, there is a lack of information and investigation carried out on the outcome of submicroscopic asymptomatic malaria in the district of Belaga and in this region. Hence, the objective of this study is to investigate the prevalence of submicroscopic malaria among asymptomatic individuals from a low transmission area in the District of Belaga, Sarawak.

\section{Methods}

\section{Study area and sample collection}

In January 2013, the Vector Borne Disease Control Programme and Sarawak Department of Health has requested the Parasitology Unit of Institute for Medical Research (IMR) to assist in the detection of suspected SMM during a malaria outbreak investigation carried out in the district of Belaga, in Kapit, Sarawak. Belaga is located in the upper reaches of the Rajang River, some $120 \mathrm{~km}$ northeast of Kapit but considerably further on the river and slightly less than $100 \mathrm{~km}$ from the South China Sea coast near Bintulu. Belaga is considered a good place to start exploring the Sarawak's interior. There are many ethnic minorities co-habituating riversides such as the Kenyah and Kayan longhouses along the Balui and Belaga rivers, and along the Rejang Rivers are the Punan, Sekapan, Kejaman and Tanjung longhouses. The total population in Belaga in 2013 was 39,400, with the malaria incidence rate of 2.9 per 1000 population. Subsequently, in 2014 and 2015, the malaria incidence rate was reduced to 2.7 and 1.6 per 1000 population, respectively. Despite continuous efforts to eradicate and eliminate malaria in this district, the infection persists. With the aim to demonstrate the presence of submicroscopic malaria in Belaga, a total number of 1744 dried blood spot samples (DBS) were collected during the routine Active Case Detection (ACD) from 8 localities within the district of Belaga in Sarawak, namely Long Malim, Long Wat,
Long Jaik, Long Tanyit, Lusong Laku/SK Lusong Laku, Rh Udau Tedong, Uma Pawa Tr Eric, and Simpang Uma Nyaving (Fig. 1). DBS were sent to the Parasitology Unit in the IMR for molecular identification. Blood films were examined by microscopists from the Sarawak Department of Health. Subsequently, in 2014, further investigation was carried out in two localities (Long Malim and Long Wat) which were selected based on the presence of PCR-diagnosed P. vivax detected during the 2013 outbreak investigation activity. However, the residents from Long Malim and Long Wat were currently relocated to a new Tegulang Resettlement Site. The total population of Long Malim and Long Wat in 2014 was 253 and 321, with an incidence rate of 4.0 and 0 per 1000 population, respectively. In 2014, both longhouses reported zero malaria incidence by microscopic examination. A total of 112 and 139 blood samples in EDTA and blood films were collected from Long Malim and Long Wat, in October 2014 respectively.

\section{Blood sample collection and preparation}

Finger prick blood $(0.1-0.2 \mathrm{ml})$ were spotted on $3 \mathrm{MM}$ Whatman filter paper (Whatman, Maidstonem, UK), air dried, individually kept in zip-lock plastic bags with desiccants and were sent to the Parasitology Unit Laboratory for DNA extraction from the first investigation. For the second investigation, approximately $1-5 \mathrm{ml}$ of venous blood was drawn in a syringe and transferred to a vacuum tube containing anticoagulant (EDTA). EDTA blood samples were stored in a $4{ }^{\circ} \mathrm{C}$ refrigerator until being processed. The remaining blood in the syringe was spotted on 3MM Whatman filter papers, air dried and individually kept in zip-lock plastic bags with desiccants for future use. For each of the finger-prick and venous blood sample, a portion of the blood was utilized directly to prepare thick and thin blood smears for microscopic analysis in both investigations. All individuals and all age groups were invited to participate in the study. Signed informed consents were obtained from all participants before enrolment. Interviews were performed with parents and/or legal guardians for participants 7 years or younger. The participant's history of previous malaria infection, occupation, age and gender, were recorded at the time of enrolment for the second set of sampling.

\section{Microscopic examination}

Thin and thick blood films for the initial investigation were prepared and examined by personnel and microscopists from the Sarawak Health Department, MOH. On the other hand, thin and thick blood films from the second investigation were prepared in separate slides and labelled accordingly at the sites. Thin blood films were dried and fixed using absolute methanol while thick 


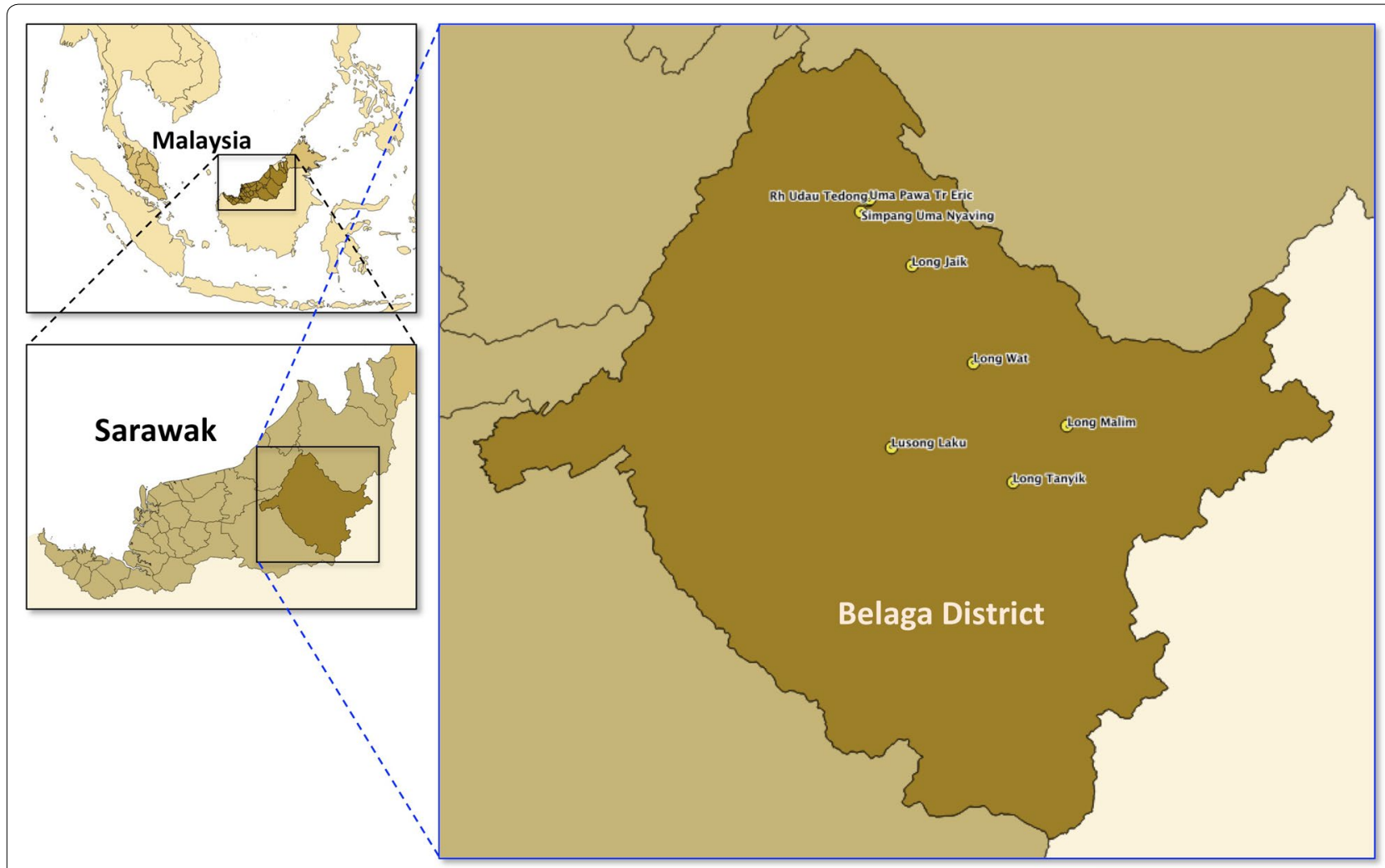

Fig. 1 Map of Belaga District with the location of the 8 localities of longhouses in this study

blood films were left to dry thoroughly. Both blood films were stained with $3 \%$ Giemsa for $45 \mathrm{~min}$ to $1 \mathrm{~h}$. Blood films were examined by two trained microscopists who had over 10 years of experience in reading malaria slides and their proficiency were periodically evaluated by local/regional quality assurance programs of the Ministry of Health Malaysia. Identification of malaria species was done using the thin blood smear while parasitaemia was examined using thick blood smear.

\section{DNA extraction}

DNA was extracted from DBS collected in the initial study using the QIAGEN DNeasy ${ }^{\circledR}$ Blood \& Tissue Kit following manufacturer's protocol with slight modification. Three $3-\mathrm{mm}^{2}$ filter paper punches, equivalent to approximately 10-15 $\mu$ l blood was excised using a puncher and transferred into a $1.5 \mu \mathrm{l}$ tube individually. DNAs from $200 \mu \mathrm{l}$ of venous blood samples collected in Vacutainer ${ }^{\circledR}$ EDTA tubes on the second study were extracted using the QIAamp ${ }^{\circledR}$ Blood Kit following manufacturer's recommendation.

\section{Detection of malaria species by PCR}

The nested PCR assay was performed on samples from the pilot study as previously published by Snounou et al. [6] and Singh et al. $[8,12]$ with slight modification. Five microliter of DNA was used as template in the first amplification process (nest 1 ) and subsequently $2 \mu$ lif the nest 1 product was used as template in nest 2 amplification. The method is based in the amplification of a region of the small subunit of the ribosomal gene (18S RNA) of Plasmodium species and the primers are listed in Table 1. Known positive and negative samples from previous malaria diagnosed or uninfected individuals were used as controls. The semi-nested multiplex PCR (NM-PCR) was performed on samples from the second study as previously described [13-15] with slight modification. Five microliter of DNA was used as template in the first amplification process. The method is based in the amplification of a region of the small subunit of the ribosomal gene (18S rRNA) of form A (asexual) of Plasmodium species. This method is a semi-nested multiplex PCR using a single reaction for the second amplification with a mixture of five specific primers for each human and one zoonotic Plasmodium species, and a universal Plasmodium primer. The nucleotide sequence (Table 2) of the primer PLF and NewPLFshort is identical for all 
Table 1 List of primers including name, nucleotide sequence, PCR step, fragment size and specificity of the nested PCR $[6,8,12]$

\begin{tabular}{|c|c|c|c|c|c|}
\hline & Plasmodium spp. & Size (bp) & Primer name & Primer sequences & PCR (T) \\
\hline Nested 1st round & Genus-specific & $1600-1700$ & $\begin{array}{l}\text { rPLU1 } \\
\text { rPLU5 }\end{array}$ & $\begin{array}{l}\text { TCAAAGATTAAGCCATGCAAGTGA } \\
\text { CCTGTTGTTGCCTTAAACTTC }\end{array}$ & $56^{\circ} \mathrm{C}$ \\
\hline Nested 2nd round & Genus-specific & 235 & $\begin{array}{l}\text { rPLU3 } \\
\text { rPLU4 }\end{array}$ & $\begin{array}{l}\text { TTTTTATAAGGATAACTACGGAAAAGCTGT } \\
\text { CCCGTCATAGCCATGTTAGGCCAATACC }\end{array}$ & $59^{\circ} \mathrm{C}$ \\
\hline \multirow[t]{5}{*}{$\begin{array}{l}\text { Nested } 2 \text { nd round spe- } \\
\text { cies specific }\end{array}$} & P. vivax & 121 & $\begin{array}{l}\text { rVIV1 } \\
\text { rVIV2 }\end{array}$ & $\begin{array}{l}\text { CGCTTCTAGCTTAATCCACATAACTGATAC } \\
\text { ACTTCCAAGCCGAAGCAAAGAAAGTCCTTA }\end{array}$ & $60^{\circ} \mathrm{C}$ \\
\hline & P. falciparum & 206 & $\begin{array}{l}\text { rFAL1 } \\
\text { rFAL2 }\end{array}$ & $\begin{array}{l}\text { TTAAACTGGTTTGGGAAAACCAAATATATT } \\
\text { ACACAATGAACTCAATCATGACTACCCGTC }\end{array}$ & \\
\hline & P. ovale & 226 & $\begin{array}{l}\text { rOVA1 } \\
\text { rPLU2 }\end{array}$ & $\begin{array}{l}\text { ATCTCTTTTTGCTATTTTTTAGTATTGGAGA } \\
\text { ATCTAAGAATTTCACCTCTGACATCTG }\end{array}$ & \\
\hline & P. malariae & 145 & $\begin{array}{l}\text { rMAL1 } \\
\text { rMAL2 }\end{array}$ & $\begin{array}{l}\text { ATAACATAGTTGTACGTTAAGAATAACCCC } \\
\text { AAAATTCCCATGCATAAAAATTATACAAA }\end{array}$ & \\
\hline & P. knowlesi & 153 & $\begin{array}{l}\text { Pmk8 } \\
\text { Pmkr9 }\end{array}$ & $\begin{array}{l}\text { GTTAGCGAGAGCCACAAAAAAGCGAAT } \\
\text { ACTCAAAGTAACAAAATCTTCCGTA }\end{array}$ & $61{ }^{\circ} \mathrm{C}$ \\
\hline
\end{tabular}

Table 2 List of primers including name, nucleotide sequence, final concentration, PCR step, fragment size and specificity of the NM-PCR [13-15]

\begin{tabular}{|c|c|c|c|c|c|}
\hline Name & Sequence $5^{\prime}-3^{\prime}$ & $\begin{array}{l}\text { Final concentration } \\
(\mu \mathrm{M})\end{array}$ & PCR $\left(T^{a}\right)$ & Size $^{\mathrm{a}}(\mathrm{bp})$ & Specificity \\
\hline PLF & AGTGTGTATCAATCGAGTTTC & 0.0375 & $\begin{array}{l}1^{\circ} \mathrm{PCR} \\
58^{\circ} \mathrm{C}\end{array}$ & $783-821^{b}$ & Plasmodium \\
\hline REV & GACGGTATCTGATCGTCTTC & 0.0375 & $\begin{array}{l}1^{\circ} \mathrm{PCR} \\
58^{\circ} \mathrm{C}\end{array}$ & - & Universal \\
\hline HUF & GAGCCGCCTGGATACCGC & 0.00625 & $\begin{array}{l}1^{\circ} \mathrm{PCR} \\
58^{\circ} \mathrm{C}\end{array}$ & 231 & Human \\
\hline NewPLFshort & CTATCAGCTTTTGATGTTAG & 0.0375 & $\begin{array}{l}2^{\circ} \mathrm{PCR} \\
53^{\circ} \mathrm{C}\end{array}$ & - & Plasmodium \\
\hline Malshort & TCCAATTGCCTTCTG & 0.0625 & $\begin{array}{l}2^{\circ} \mathrm{PCR} \\
53^{\circ} \mathrm{C}\end{array}$ & 215 & P. malariae \\
\hline Falshort & GTTCCCCTAGAATAGTTACA & 0.0375 & $\begin{array}{l}2^{\circ} \mathrm{PCR} \\
53^{\circ} \mathrm{C}\end{array}$ & 344 & P. falciparum \\
\hline Vivshort & AAGGACTTCCAAGCC & 0.025 & $\begin{array}{l}2^{\circ} \mathrm{PCR} \\
53^{\circ} \mathrm{C}\end{array}$ & 457 & P. vivax \\
\hline OvaNew & CCAATTACAAAACCATG & 0.0875 & $\begin{array}{l}2^{\circ} \mathrm{PCR} \\
53^{\circ} \mathrm{C}\end{array}$ & 176 & P. ovale \\
\hline NewPKrev & CGCGGAGGCATC & 0.025 & $\begin{array}{l}2^{\circ} \mathrm{PCR} \\
53^{\circ} \mathrm{C}\end{array}$ & 389 & P. knowlesi \\
\hline
\end{tabular}

${ }^{a}$ Expected size of the PCR product between the corresponding Universal/Plasmodium primer with the species specific primer

b Size depending upon species

Plasmodium species including the ones which infect human, monkeys, other mammalian, birds and other vertebrates. Uninfected human blood was used as negative control.

\section{Results}

\section{Sampling characteristics}

A total of 1744 DBS were received from the Sarawak Health Department in 2013, together with microscopic examination results, previously read by microscopists from the Sarawak Health Department. Data on age, gender, exposure and travel history or occupation were considered confidential thus not provided to us (Parasitology Unit, IMR). The DBS were collected from 8 localities in the district of Belaga (Table 3). A total of 251 whole blood in EDTA and Giemsa-stained blood films from two localities (Long Malim and Long Wat) in the District of Belaga, Sarawak in 2014 were brought back to the Parasitology Unit of the Institute for Medical Research Kuala Lumpur for laboratory diagnosis. The 
Table 3 Prevalence of submicroscopic malaria from bloodspot received from Belaga District in 2013 confirmed by nested PCR

\begin{tabular}{|c|c|c|c|c|c|}
\hline \multirow[t]{2}{*}{ Locality in Belaga district } & \multirow{2}{*}{$\begin{array}{l}\text { No. of bloodspots } \\
\text { received }\end{array}$} & \multirow{2}{*}{$\begin{array}{l}\text { Malaria positive } \\
\text { by microscopy }\end{array}$} & \multicolumn{2}{|c|}{ Nested PCR assay } & \multirow{2}{*}{$\begin{array}{l}\text { Proportion } \\
\text { PCR (\%) }\end{array}$} \\
\hline & & & P. vivax & $\begin{array}{l}\text { Other Plasmodium } \\
\text { sp. }\end{array}$ & \\
\hline Long Malim & 383 & 0 & 9 & 0 & 0.5 \\
\hline Long Wat & 90 & 0 & 3 & 0 & 0.2 \\
\hline Long Jaik & 173 & 0 & 3 & 0 & 0.2 \\
\hline Long Tanyit & 177 & 0 & 1 & 0 & 0.1 \\
\hline Lusong Laku/SK Lusong Laku & 567 & 0 & 4 & 0 & 0.2 \\
\hline Rh Udau Tedong & 126 & 0 & 5 & 0 & 0.3 \\
\hline Uma Pawa Tr Eric & 77 & 0 & 0 & 0 & 0 \\
\hline Simpang Uma Nyaving & 151 & 0 & 2 & 0 & 0.1 \\
\hline Belaga distrct & 1744 & 0 & 27 & 0 & 1.5 \\
\hline
\end{tabular}

Table 4 Prevalence of submicroscopic malaria from study samples collected from Long Malim and Long Wat in 2014 confirmed by semi-nested multiplex PCR

\begin{tabular}{|c|c|c|c|c|c|c|c|c|c|}
\hline \multirow[t]{2}{*}{ Variable Factor } & \multicolumn{3}{|c|}{ Long Malim } & \multicolumn{3}{|l|}{ Long Wat } & \multicolumn{3}{|l|}{ Total } \\
\hline & $\begin{array}{l}\text { No. } \\
\text { of sample } \\
\text { tested }\end{array}$ & PCR positive & $\begin{array}{l}\text { PCR } \\
\text { positive } \\
(\%)\end{array}$ & $\begin{array}{l}\text { No. } \\
\text { of sample } \\
\text { Tested }\end{array}$ & PCR positive & $\begin{array}{l}\text { PCR } \\
\text { positive } \\
(\%)\end{array}$ & $\begin{array}{l}\text { No } \\
\text { of sample } \\
\text { Tested }\end{array}$ & pcr positive & $\begin{array}{l}\text { PCR } \\
\text { positive } \\
(\%)\end{array}$ \\
\hline \multicolumn{10}{|l|}{ Gender } \\
\hline Female & 53 & 31 & 58.5 & 62 & 35 & 56.5 & 115 & 66 & 57.4 \\
\hline Male & 59 & 24 & 40.7 & 77 & 28 & 36.4 & 136 & 52 & 38.2 \\
\hline \multicolumn{10}{|l|}{ Age group } \\
\hline 0-5 y/o (pre-school children) & 0 & 0 & 0 & 1 & 0 & 0 & 1 & 0 & 0 \\
\hline 6-16 y/o (School children) & 12 & 7 & 58.3 & 18 & 10 & 55.6 & 30 & 17 & 56.7 \\
\hline $\begin{array}{l}17 \geq_{\text {, (household income }} \\
\text { earners/housewives) }\end{array}$ & 100 & 48 & 48.0 & 120 & 53 & 44.2 & 220 & 101 & 45.9 \\
\hline \multicolumn{10}{|l|}{ PCR-confirmed malaria species } \\
\hline P. falciparum & 55 & 26 & 47.2 & 63 & 24 & 38.1 & 118 & 50 & 42.4 \\
\hline P. vivax & & 18 & 32.7 & & 21 & 33.3 & & 39 & 33.1 \\
\hline P. knowlesi & & 9 & 16.4 & & 0 & 0 & & 9 & 7.6 \\
\hline Mixed $P f+P v$ & & 1 & 1.8 & & 16 & 25.4 & & 17 & 14.4 \\
\hline Mixed $P v+P k$ & & 1 & 1.8 & & 2 & 3.2 & & 3 & 2.5 \\
\hline Total & 112 & 55 & 49.1 & 139 & 63 & 45.3 & 251 & 118 & 47.0 \\
\hline
\end{tabular}

study population consisted of infants to pre-schooled children (1\%), school children (12\%) and those above 17 years old (87\%) who are either household income earners or housewives (Table 4 ). The male to female ration this study was 1.1 male to 1 female. Most female above the age of 17 (86\%) are housewives while male above the age of 17 and below the age of 70 (82\%) are mostly farmers and loggers, while some works at the oil palm plantation. Children within the age 7 to 16 are mostly in school located near to their longhouses. None of the tribal villagers from both studies reported malaria-like illness and appeared reasonably healthy during blood sampling activity.

\section{Confirmation of submicrosopic malaria by nested PCR assays}

No malaria parasites were seen by microscopic examination of Giemsa-stained thick and thin blood films collected from the 2013 and 2014 studies (Tables 3 and 4). Nested PCR protocol detected 27 (1.6\%) P. vivax and none were positive for other malaria species. Sources of DBS samples received were from 8 localities listed in 
Table 4. Long Malim had the highest prevalence of Plasmodium infections; $0.5 \%$ (9/1744), followed by Rh. Udau Tedong, Lusong Laku/SK Lusong Laku, Long Wat, Long Jaik, Simpang Uma Nyaving and Long Tanyit with $0.3 \%$ (5/1744), $0.2 \%$ (4/1744). $0.2 \%$ (3/1744), $0.2 \%$ (3/1744), $0.1 \%(2 / 1744)$ and $0.05 \%(1 / 1744)$, respectively. From the total of 251 blood samples obtained in the second study, 118 (47\%) samples were tested positive for Plasmodium sp. by PCR (Table 4). Interestingly, malaria infection attributed to not only $P$. vivax, but also to $P$. falciparum and $P$. knowlesi were found. Mono-infections of $P$. vivax, $P$. falciparum or $P$. knowlesi were in proportions of $15 \%$, $20 \%$ and 4\%, respectively; while mixed infection of $P$. vivax and $P$. falciparum accounted for $7 \%$ and mixed infection of $P$. vivax and P. knowlesi accounted for $1 \%$ of total blood samples tested by PCR. In Long Malim, the most prevalent species was $P$. falciparum with 26 cases (47.2\%), followed by P. vivax, P. knowlesi and mixed infections with 18 (32.7\%), 9 (16.4\%) and 2 (3.6\%), respectively. In Long Wat, the prevalence of $P$. falciparum was also the highest with 24 cases (38.1\%) followed by $P$. vivax and mixed infections with 21 (33.3\%) and 18 (28.6\%), respectively. There were no mono-infections of $P$. knowlesi detected from Long Wat. There is no significant difference between the prevalence of malaria parasites in both localities $(\mathrm{P}=0.55)$. Within Long Malim $(\mathrm{P}=0.22)$ and Long Wat $(\mathrm{P}=0.32)$, there was no significant difference between the prevalence of malaria species in both gender. Both genders are equally at risk of harbouring submicroscopic malaria within the population.

\section{Discussion}

Currently, the Malaysia is in the elimination phase of the human-only Plasmodium species and proposes to eliminate malaria by the year 2020 based on World Health Organization (WHO) efforts, and the Malaysian National Malaria Control Programme. In 2018, Malaysia had approximately 4630 malaria cases, where $P$. knowlesi accounted for $89 \%$ of the total number of cases reported and $11 \%$ for the human malaria cases (imported and introduced). The substantial decrease of $P$. falciparum and $P$. vivax cases gives rise to $P$. knowlesi, and this trend threatens malaria elimination. Although SMM have been reported from Southeast Asian countries (Thailand, Indonesia, Myanmar, Cambodia and Vietnam) with the prevalence rate of between 1.7 and 36\% [5, 16-22], limited data about such carriage are reported in Malaysia. Only two studies in Malaysia has reported prevalence of asymptomatic SMM $[5,18]$. In addition to that, with the presence P. knowlesi, a zoonotic malaria parasite maintained by macaques, that has been described throughout Southeast Asia is now the most common cause of human malaria in Malaysian Borneo [23]. In 2013 and 2014, the number of malaria cases reported in Kapit Division is 204 and 219 respectively. In 2013, there were 10 cases of $P$. falciparum, 170 cases of $P$. knowlesi, 4 cases of $P$. malariae and 7 cases of $P$. vivax. The number increased substantially in 2018 with 51 cases of P. falciparum, 267 P. knowlesi, and 43 cases of $P$. vivax. This data shows that despite efforts taken to control and prevent the disease, the number is still increasing. However, there is lack of evidence for or against a substantive role of submicroscopic malaria for transmission in this country. This makes the ethics of treating asymptomatic and submicroscopic parasitaemia unclear and dependent on the risk-benefit ratios of the treatment and/or prevention strategies being implemented. While Malaysia has a malaria elimination goal of zero indigenous transmission for all human malaria species by 2020, achieving malaria elimination requires targeting the human reservoir of infection, including those with asymptomatic infection which requires the combination of universal coverage of interventions with implementation of a robust surveillance system that collects, transmits, and analyses data about cases and programme activities in real time to inform rapid response strategies. The current study adds to the available evidence on the presence of submicroscopic parasitaemia in this country. Accurate diagnosis of asymptomatic SMM is important for providing realistic estimates of malaria burden and preventing misinformed interventions. However, it is not an easy task as low levels of parasitaemia may act as silent reservoir of transmission thus remains infectious to susceptible mosquito vectors. In this study, Since the transmission of malaria parasites from humans to mosquitoes requires the presence of gametocytes, any strategy that interferes with the development or persistence of gametocytes should help to interrupt transmission [4, 24-26]. In most malaria endemic areas, the majority of parasite carriers are asymptomatic. Asymptomatic individuals carrying gametocytes remain available as a reservoir for transmission by mosquitoes, contributing to the persistence of malaria transmission within local populations. It is important to carry out more research to understand better the contribution of submicroscopic infections in malaria transmission in low endemic settings and to identify which diagnostic strategies are most reliable. This can be done, either by retrospective molecular analysis of prior cohort studies where only microscopy was used, or prospectively, in the context of cohort studies and national surveys, in which microscopy-negative but PCR-positive subjects are followed and not treated unless they become symptomatic or develop patent parasitaemia [27].

While a systematic review indicated a relationship between microscopy and polymerase chain reaction (PCR) prevalence, the proportion of all infections in a 
population which are submicroscopic is not predictable in any given situation, particularly in areas of low transmission. Thus, when quantification of submicroscopic infections is needed, this has to be measured directly. Submicroscopic cases are often associated with asymptomatic malaria parasite carriers especially adults. Microscopic diagnosis using thick and thin blood smears plays an important role in malaria diagnosis because of its ability to diagnose and differentiate each species of malaria, and so it is used as the gold standard for any new detection tool or technique [28]. Nonetheless, microscopy has been found to have a great number of limitations. A superior and a more reliable diagnostic technique need to be put in place to enable proper treatment and control of malaria. A good microscopist can identify 50 parasites per $\mu \mathrm{l}$ blood $(\mathrm{p} / \mu \mathrm{l})$ while the expert microscopist will struggle to detect regularly infections $<20 \mathrm{p} / \mu \mathrm{l}$ (Chiodini, pers. commun.). Furthermore, the diagnostic accuracy relies on the quality of the blood smear and experience of laboratory personnel. Malaria microscopy is time consuming, requires skilled laboratory technicians and is often subject to unreliable results from different laboratories [29]. In recent years, alternative methods to identify malaria infections with varying degrees of specificity and sensitivity have been developed. These include fluorescence microscopy of malaria parasites stained with acridine orange, dipstick immunoassays that detect species-specific parasite antigens, and, more recently, detection of parasite nucleic acids after amplification by PCR. With some of these methods, sensitivities and specificities approaching and even exceeding those of the thin and thick film can be attained [30].

The WHO recommends prompt parasitological confirmation of diagnosis by either good quality microscopy or good quality RDTs before treatment is being administered [31]. Nonetheless, many of these asymptomatic infections are present at densities below the limit for microscopic detection and, therefore, use of microscopy or RDT is likely to lead to underestimation of the malaria burden [32, 33]. In developing world where malaria is highly prevalent, the resources to aid in proper and accurate diagnosis are lacking and has led to improper administration of anti-malarial drugs [34]. A number of different PCR diagnostic techniques exist: single step, nested, multiplex and quantitative. Alternative nucleic acid amplification (NAA) techniques have been developed which do not need thermocyclers, the most common are loop-mediated isothermal amplification (LAMP) and nucleic acid sequence-based amplification (NASBA). In this study, the nested PCR $[6,8,12]$ and semi-nested multiplex PCR [13-15] assays were used with slight modification. The nested PCR assay has a limit of detection of at least 6 parasites/ $\mu$ l for blood spots. It has a much higher sensitivity compared to the single step PCR for four major Plasmodium species. Meanwhile, the semi-nested multiplex method developed by Rubio et al. [13-15] has a limit of detection of 0.01 parasites/ $\mu \mathrm{l}$ of blood and is able to detect all human and knowlesi malaria simultaneously. The villagers of Long Malim and Long Wat in the initial study were relocated to a new resettlement (Tegulang Resettlement Site) approximately $20 \mathrm{~km}$ from their original locality within the District of Belaga under the Murum Resettlement Scheme. In this study, there is a large discrepancy in prevalence from the study samples in 2013 to the 2014 cohort tested (1.65 vs. $47 \%$ ). This could not merely be due to the better limit of detection (LOD) seen in the semi-nested multiplex PCR as compared to the method used in the initial study (6 parasites/ $\mu$ l of blood), but the major contributing reason would appear to be the blood volumes for which DNA was extracted from i.e. filter paper $(10-15 \mu \mathrm{l})$ as opposed to whole blood $(200 \mu \mathrm{l})$. Further studies should be carried out in these areas as there are various factors to the difference of incidence of asymptomatic SMM in both studies. This could possibly indicate that there is high prevalence of submicrosopic and asymptomatic malaria infections in Belaga or due the fact that two different method of detection (nested PCR vs semi-nested multiplex PCR) and two different samples (dried blood spots vs whole blood) were collected during the first and second study, respectively. In 2013, 2 of the villages (Long Malim and Long Wat) where the initial sampling took place were displaced to give way to the Murum HydroElectric Power Project. The communities of Long Wat, Long Malim (Penan) and the Long Malim (Kenyah) have agreed to be resettled at the Tegulang River, which was where the second sampling took place. The villagers of Long Malim and Long Wat comprises of the Penan and Kenyah ethnic communities. The economy of Murum Penan communities consists of farming and forest based activities such as hunting, fishing and gathering of forest products while the Kenyah community at Long Malim have long been living a settled life centred on agriculture activities such as planting hill paddy [35].

In general, challenges in developing multiplex PCR systems include difficulties in designing primers and optimal conditions for a highly sensitive and specific assay. The specificity of the primers for each species is essential in order to get good results in the identification of each species and avoid false negatives and misidentifications [14, 36-38]. In a malaria epidemiological survey, especially in low transmission area such as Belaga, a substantial proportion of malaria infections are missed by microscopy and/or RDTs because of low parasite-density infections. Generally, the use of highly sensitive diagnostic tools should be considered only in low-transmission settings 
where there is already widespread malaria diagnostic testing and treatment and low parasite prevalence rates (e.g. $<10 \%)$. It is also important to note that submicroscopic $P$. falciparum and $P$. vivax infections are common in both low and high transmission settings. Use of NAA methods in malaria programmes should be considered for epidemiological research and surveys to map submicroscopic infections in low transmission areas. NAA methods might also be used for identifying foci for special interventions in elimination settings. According to Okell et al. [32], there is an association between transmission intensity and the proportion of infections that are submicroscopic. Their findings suggests that, as the underlying PCR prevalence increased, the microscopy: PCR prevalence ratio also increased (the prevalence ratio was 1.135 times higher per $10 \%$ increase in PCR prevalence [95\% CI 1.051-1.226]; $\mathrm{P}=0.002$ ). This finding also suggests that a higher proportion of infections are undetected by microscopy in areas with low levels of transmission. Thus, in studies where the PCR prevalence in the study population was $<10 \%$, microscopy detected only $12.0 \%$ of the infections that were identified by PCR $(95 \%$ CI 4.8-29.9\%), whereas in studies in which the PCR prevalence was $\geq 75 \%$, microscopy detected $74.5 \%$ of infections (95\% CI 67.1-82.8\%). However, submicroscopic infections are of particular relevance in low-transmission areas aiming for elimination, where they are likely to sustain transmission if not detected [32] and the main problem with PCR is contamination with rates of $0.7-10 \%$ reported by laboratories [39], and it would be expected to have the biggest effect in low-transmission settings, where a higher proportion of samples have true-negative results. There is a need for development of a standardized PCR for parasite detection especially in low transmission areas. Another experimental explanation for the observed association could be that microscopists are less experienced in identifying malaria in settings where transmission is lower.

Asymptomatic SMM has rarely been a major research focus. In malaria endemic areas, asymptomatic malaria parasite carriers especially adults are not uncommon and, as potential gametocyte carriers, represent an important reservoir for malaria transmission [40]. Asymptomatic SMM may serve as a reservoir for infection even when very efficient rapid diagnosis and treatment programmes have been implemented [41]. In malaria endemic areas, continuous exposure to Plasmodium parasites leads to asymptomatic carriers that provide a fundamental reservoir of parasites, contributing to the persistence of malaria transmission [42]. Particularly, subpatent malaria is still transmissible and will complicate elimination of malaria in high transmission regions. A major obstacle in the study of asymptomatic malaria is the lack of standard diagnostic criteria. Quantifying parasitaemia, rather than documenting presence or absence of parasites, may also be an important consideration when diagnosing asymptomatic malaria. However, a universally standard parasite threshold for classifying an infection as asymptomatic has yet to be defined, as different studies use variable cutoff levels for parasite density [23, 43, 44]. Though the use of species-specific PCR possible is not always available in the field, or even perhaps practical for testing infections that are negative by microscopy, it is a powerful tool for finding asymptomatic malaria within a population. Various studies found that as many as two-thirds of the microscopy-negative patients had subpatent levels of parasites determined by diagnostic PCR, indicating that almost the entire population was chronically infected with asymptomatic malaria [45-48]. There is some indication that very low-density $P$. vivax infections do contribute to ongoing transmission but data are very limited $[49,50]$. It is also apparent that RDT and microscopy do not detect the full prevalence of $P$. vivax infection because of the large proportion of submicroscopic infection in low transmission settings.

Due to time constraint, the detection of gametocytaemia of $P$. falciparum and P. vivax were not carried out. Since the transmission of malaria parasites from humans to mosquitoes requires the presence of gametocytes, any strategy that interferes with the development or persistence of gametocytes should help to interrupt transmission. In most malaria endemic areas, the majority of parasite carriers are asymptomatic. Asymptomatic individuals carrying gametocytes remain available as a reservoir for transmission by mosquitoes, contributing to the persistence of malaria transmission within local populations. It is vital to determine the gametocyte carriage potential of individuals followed without treatment and to identify surrogate markers of latent $P$. vivax infection because currently there is no diagnostic tool which is able to directly detect latent $P$. vivax. Studies of duration of infection, submicroscopic gametocyte carriage, and gametocyte production potential need to be carried out in submicroscopic infections in low transmission settings where elimination is being considered. This can be done, either by retrospective molecular analysis of prior cohort studies where only microscopy was used, or prospectively, in the context of cohort studies and national surveys, in which microscopy-negative but PCR-positive subjects are followed and not treated unless they become symptomatic or develop patent parasitaemia.

For malaria elimination settings it is critical to detect all infections, including those with low and sub-microscopic parasite densities in asymptomatic carriers as they represent a parasite reservoir in the community capable of effectively transmitting infections to mosquitoes $[4,25]$ 
and seeding transmission foci [10]. It is well known that malaria epidemiology varies between country and region, and particularly between islands, because the dominant vector species, the characteristics of human populations and factors that influence transmission such as rainfall, temperature, housing conditions and population movement differ. Therefore, the challenges to malaria elimination in different settings will vary. Each area needs to investigate the malaria epidemiology and carefully tailor its diagnosis strategy to the local context. In part, the use of molecular assays such as PCR to detect parasite DNA has improved the sensitivity of diagnostics to find subpatent (i.e. below the detection limits for microscopy) infections that are more likely to be asymptomatic, and this has contributed to the understanding of the extent of the asymptomatic parasite reservoir [33]. As the magnitude of the asymptomatic parasite reservoir has been revealed through increasing use of more sensitive molecular diagnostic methods, new strategies to target individuals with silent infections are being developed and evaluated.

\section{Conclusion}

Submicroscopic infections are thought to be important contributors to maintaining malaria transmission. However, there is currently no direct evidence that specifically targeting this low-density parasite reservoir will hasten progress towards elimination. In most malaria endemic settings, asymptomatic infections outnumber symptomatic infections. The objective of this study was to detect the presence of submicroscopic malaria in low transmission area. It was achieved with by using molecular methods. The semi-nested multiplex PCR has proven to be a very useful tool in detection of asymptomatic submicroscopic malaria in both high and low transmission area. However, the WHO does not currently provide guidance to countries regarding the programmatic suitability of molecular diagnostics or guidelines on how to utilize the information that would emerge from their use. Quality assured microscopy is still officially considered the gold standard by the WHO, despite large bodies of evidence that shows that PCR and other nucleic acid amplificationbased assays are more sensitive than microscopy. There is a need to develop guidance on indications for use, assay selection and quality assurance/control for PCR and other molecular diagnostic techniques for the specific conditions in which use of these malaria diagnostic tools may be appropriate. In this study, P. knowlesi infections were also detected among the population. It remains unknown if and how much humans contribute to the infectious reservoir for $P$. knowlesi transmission. While the submicroscopic parasite densities of other malaria species have been shown to be capable of infecting mosquitoes, all experimental infections with $P$. knowlesi have been from clinical malaria cases. As demonstrated by the data from this study, the most common cause of asymptomatic SMM is $P$. falciparum and followed $P$. vivax, despite the fact that $P$. knowlesi is present. These results illustrate the possibility that by the time a person is symptomatic, the parasite load would have risen by many folds. This is an important aspect to be considered by public health personnel as well as clinicians on whether there is need to heighten surveillance or to make PCR detection routine. The occurrence of other possible zoonotic species also needs to be further elucidated. Unfortunately, this study did not cover that aspect and since this is one of the first community-based studies, more studies needs to be conducted to confirm this. Entomological and primatological studies are also needed to evaluate the presence of potential $P$. knowlesi vectors in these village environments and the proximity of infected reservoirs.

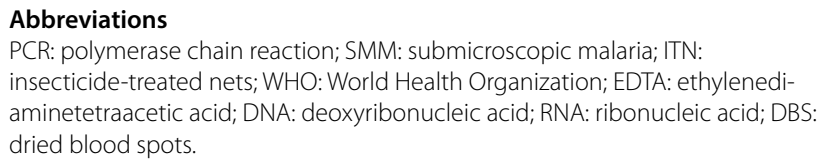

\section{Authors' contributions}

AlJ and SH designed the study. $\mathrm{CHO}$ provided bloodspot on filter paper samples and assisted in arrangement of field survey in Belaga. JMR assisted in molecular genetic studies. AIJ, GK, and MMA collected and prepared samples. GK, MMA and NPI examined blood smears. AIJ, NMS and NWA extracted DNA, performed PCR and compiled data. AIJ wrote the article. SH discussed and reviewed the manuscript. All authors read and approved the final manuscript.

\section{Author details}

${ }_{1}^{1}$ Parasitology Unit, Infectious Diseases Research Centre, Institute for Medical Research, Ministry of Health Malaysia, Jalan Pahang, 50588 Kuala Lumpur, Malaysia. ${ }^{2}$ Vector Borne Diseases Section, Sarawak Health Department, Ministry of Health Malaysia, Diplomatik Road, Off Bako Road, Petra Jaya, 93050 Kuching, Sarawak, Malaysia. ${ }^{3}$ Malaria \& Emerging Parasitic Diseases Laboratory, Parasitology Department, National Centre of Microbiology, Instituto de Salud Carlos III (ISCIII), Carretera de Majadahonda - Pozuelo, km. 2,200, Majadahonda, 28220 Madrid, Spain.

\section{Acknowledgements}

The authors would like to thank the Director General of Health Malaysia and the Director of IMR for permission to publish this article. The authors would also like to thank all staff and colleagues from Parasitology Unit, IMR, for their help in field and laboratory work; all staff from the Sarawak Health Department and Belaga District Health Office for their assistance and contribution to this study especially during sample collection.

\section{Competing interests}

The authors declare that they have no competing interests.

\section{Availability of data and materials}

The datasets used and/or analysed during the current study are available from the corresponding author on reasonable request.

\section{Consent for publication}

Written informed consent was obtained from study subjects for participation in the study and for publication of this report. Consent and approval for publication was also obtained from Director General of Health, Malaysia. 


\section{Ethics approval and consent to participate}

This study was approved by the Medical Research \& Ethics Committee (MREC), Ministry of Health Malaysia (NMRR-13-1064-18189). Following consultation with and approval by community leaders, community meetings were held to explain the aims, risks and potential benefits of the study. Individual informed consent was obtained from all participants or the parent or legal guardian of children $<18$ years of age. At the point of collection, all samples were de-identified.

\section{Funding}

This study was funded by the Ministry of Health Grant (JPP-IMR 13-044) (NMRR-13-1064-18189).

\section{Publisher's Note}

Springer Nature remains neutral with regard to jurisdictional claims in published maps and institutional affiliations.

Received: 8 February 2019 Accepted: 22 April 2019

Published online: 02 May 2019

\section{References}

1. WHO. World Malaria Report 2018. Geneva: World Health Organization; 2018.

2. Disease Control Department, Vector Borne Disease Sector, MOH Malaysia Garis Panduan Pencegahan Malaria Re-Introduction di Malaysia (Malay). 2016.

3. Tiono AB, Ouédraogo A, Diarra A, Coulibaly S, Soulama I, Konaté AT, et al Lessons learned from the use of HRP-2 based rapid diagnostic test in community-wide screening and treatment of asymptomatic carriers of Plasmodium falciparum in Burkina Faso. Malar J. 2014;13:30.

4. Schneider P, Bousema JT, Gouagna LC, Otieno S, van de Vegte-Bolmer M, Omar SA, et al. Submicroscopic Plasmodium falciparum gametocyte densities frequently result in mosquito infection. Am J Trop Med Hyg. 2007;76:470-4.

5. Jiram Al, Hisam S, Reuben H, Husin SZ, Roslan A, Razuki W, et al. Submicroscopic evidence of the simian malaria parasite, P. knowlesi, in Orang Asli community. Southeast Asian J Trop Med Public Health. 2016:47:591-9.

6. Snounou G, Singh B. Nested PCR analysis of Plasmodium parasites. In: Doolan DL, editor. Malaria methods and protocols. New York: Humana Press; 2002. p. 189-204.

7. Black J, Hommel M, Snounou G, Pinder M. Mixed infections with Plasmodium falciparum and P. malariae and fever in malaria. Lancet. 1994:343:1095.

8. Singh B, Cox-Singh J, Miller AO, Abdullah MS, Snounou G, Rahman HA Detection of malaria in Malaysia by nested polymerase chain reaction amplification of dried blood spots on filter papers. Trans R Soc Trop Med Hyg. 1996;90:519-21.

9. Imwong M, Hanchana S, Malleret B, Renia L, Day NPJ, Dondorp A, et al. High-throughput ultra sensitive molecular techniques for quantifying low-density malaria parasitemias. J Clin Microbiol. 2014;52:3303-9.

10. Nguyen TN, von Seidlein L, Nguyen TV, Truong PN, Hung SD, Pham HT, et al. The persistence and oscillations of submicroscopic Plasmodium falciparum and Plasmodium vivax infections over time in Vietnam: an open cohort study. Lancet Infect Dis. 2018;18:565-72.

11. Trape JF, Zoulani A, Quinet MC. Assessment of the incidence and prevalence of clinical malaria in semi-immune children exposed to intense and perennial transmission. Am J Epidemiol. 1987;126:193-201.

12. Singh B, Sung LK, Matusop A, Radhakrishnan A, Shamsul SSG, Cox-Singh J, et al. A large focus of naturally acquired Plasmodium knowlesi infections in human beings. Lancet. 2004;363:1017-24.

13. Rubio JM, Benito A, Roche J, Berzosa PJ, García ML, Micó M, et al. Seminested, multiplex polymerase chain reaction for detection of human malaria parasites and evidence of Plasmodium vivax infection in Equatorial Guinea. Am J Trop Med Hyg. 1999;60:183-7.

14. Ta TH, Hisam S, Lanza M, Jiram Al, Ismail N, Rubio JM. First case of a naturally acquired human infection with Plasmodium cynomolgi. Malar J. 2014;13:68
15. Miguel-Oteo M, Jiram Al, Ta-Tang TH, Lanza M, Hisam S, Rubio JM. Nested multiplex PCR for identification and detection of human Plasmodium species including Plasmodium knowlesi. Asian Pac J Trop Med. 2017;10:299-304

16. Zaw MT, Thant M, Hlaing TM, Aung NZ, Thu M, Phumchuea K, et al. Asymptomatic and sub-microscopic malaria infection in Kayah State, eastern Myanmar. Malar J. 2017;16(1):138. https://doi.org/10.1186/s1293 6-017-1789-9.

17. Baum E, Sattabongkot J, Sirichaisinthop J, Kiattibutr K, Jain A, Taghavian $\mathrm{O}$, et al. Common asymptomatic and submicroscopic malaria infections in Western Thailand revealed in longitudinal molecular and serological studies: a challenge to malaria elimination. Malar J. 2016;15:333.

18. Fornace KM, Nuin NA, Betson M, Grigg MJ, William T, Anstey NM, et al. Asymptomatic and submicroscopic carriage of Plasmodium knowlesi malaria in household and community members of clinical cases in Sabah Malaysia. J Infect Dis. 2015:213:784-7.

19. Hutagalung J. Prevalence of asymptomatic submicroscopic malaria in eastern Indonesia: a cross sectional survey and spatial analysis. Lancet Glob Health. 2017:9:1-7.

20. Arwati H, Yotopranoto S, Rohmah EA, Syafruddin D. Submicroscopic malaria cases play role in local transmission in Trenggalek district, East Java Province, Indonesia. Malar J. 2018;17:2.

21. Imwong M, Nguyen TN, Tripura R, Peto TJ, Lee SJ, Lwin KM, et al. The epidemiology of subclinical malaria infections in South-East Asia: findings from cross-sectional surveys in Thailand-Myanmar border areas, Cambodia, and Vietnam. Malar J. 2015;14:381

22. Tripura R, Peto TJ, Veugen CC, Nguon C, Davoeung C, James N, et al. Submicroscopic Plasmodium prevalence in relation to malaria incidence in 20 villages in western Cambodia. Malar J. 2017:16:56.

23. Singh B, Daneshvar C. Human infections and detection of Plasmodium knowlesi. Clin Microbiol Rev. 2013;26:165-84.

24. Coalson JE, Walldorf JA, Cohee LM, Ismail MD, Mathanga D, Cordy RJ, et al. High prevalence of Plasmodium falciparum gametocyte infections in school-age children using molecular detection: patterns and predictors of risk from a cross-sectional study in southern Malawi. Malar J. 2016;15:527.

25. Coleman RE, Kumpitak C, Ponlawat A, Maneechai N, Phunkitchar V, Rachapaew N, et al. Infectivity of asymptomatic Plasmodium-infected human populations to Anopheles dirus mosquitoes in western Thailand. J Med Entomol. 2004:41:201-8.

26. Gouagna LC, Ferguson HM, Okech BA, Killeen GF, Kabiru EW, Beier JC, et al. Plasmodium falciparum malaria disease manifestations in humans and transmission to Anopheles gambiae: a field study in Western Kenya. Parasitology. 2004;128:235-43.

27. Lin JT, Saunders DL, Meshnick SR. The role of submicroscopic parasitemia in malaria transmission: what is the evidence? Trends Parasitol. 2014:30:183-90.

28. Moody AH, Chiodini PL, Work- GH. Methods for the detection of blood parasites. Clin Lab Haem. 2000;22:189-202.

29. Wilson ML. Laboratory diagnosis of malaria: conventional and rapid diagnostic methods. Arch Pathol Lab Med. 2013;137:805-11.

30. Lee SH, Kara UA, Koay E, Lee MA, Lam S, Teo D. New strategies for the diagnosis and screening of malaria. Int J Hematol. 2002;76(Suppl 1):291-3.

31. World Health Organizataion. World malaria report 2005. Geneva: World Health Organizataion; 2005.

32. Okell LC, Bousema T, Griffin JT, Ouédraogo AL, Ghani AC, Drakeley CJ. Factors determining the occurrence of submicroscopic malaria infections and their relevance for control. Nat Commun. 2012;3:1237.

33. Okell LC, Ghani AC, Lyons E, Drakeley CJ. Submicroscopic infection in Plasmodium falciparum — endemic populations: a systematic review and meta-analysis. J Infect Dis. 2009;200:1509-17.

34. Rafael ME, Taylor T, Magill A, Lim Y-W, Girosi F, Allan R. Reducing the burden of childhood malaria in Africa: the role of improved diagnostics. Nature. 2006:444(Suppl 1):39-48.

35. Proposed Resettlement Action Plan For the Murum Hydro-Electric Power Project Public Disclosure Document. Sarawak State Government 22nd May 2013. https://www.internationalrivers.org/sites/default/files/attac hed-files/murum_dam_resettlement_plan_may_2013.pdf. Accessed 13 Apr 2019. 
36. Van den Eede P, Van HN, Van Overmeir C, Vythilingam I, Duc T, Hung L, et al. Human Plasmodium knowlesi infections in young children in central Vietnam. Malar J. 2009;8:249.

37. Calderaro A, Piccolo G, Gorrini C, Rossi S, Montecchini S, Dell'Anna M, et al. Accurate identification of the six human Plasmodium spp. causing imported malaria, including Plasmodium ovale wallikeri and Plasmodium knowlesi. Malar J. 2013;12:321.

38. Shokoples SE, Ndao M, Kowalewska-Grochowska K, Yanow SK. Multiplexed real-time PCR assay for discrimination of Plasmodium species with improved sensitivity for mixed infections. J Clin Microbiol. 2009:47:975-80.

39. Wilson SM. Detection of malaria parasites by PCR. Trans R Soc Trop Med Hyg. 1994;88:363.

40. Alves FP, Gil LHS, Marrelli MT, Ribolla PEM, Camargo EP, Da Silva LHP. Asymptomatic carriers of Plasmodium spp. as infection source for malaria vector mosquitoes in the Brazilian Amazon. J Med Entomol. 2005;42:777-9.

41. Laishram DD, Sutton PL, Nanda N, Sharma VL, Sobti RC, Carlton JM, et al. The complexities of malaria disease manifestations with a focus on asymptomatic malaria. Malar J. 2012:11:29.

42. Zoghi S, Mehrizi AA, Raeisi A, Haghdoost AA, Turki H, Safari R, et al. Survey for asymptomatic malaria cases in low transmission settings of Iran under elimination programme. Malar J. 2012;11:126.

43. Rottmann M, Lavstsen T, Mugasa JP, Kaestli M, Jensen ATR, Müller D, et al. Differential expression of var gene groups is associated with morbidity caused by Plasmodium falciparum infection in Tanzanian children. Infect Immun. 2006;74:3904-11.
44. Dalla Martha RC, Tada MS, Ferreira RGDM, Da Silva LHP, Wunderlich G. Microsatellite characterization of Plasmodium falciparum from symptomatic and non-symptomatic infections from the Western Amazon reveals the existence of non-symptomatic infection-associated genotypes. Mem Inst Oswaldo Cruz. 2007;102:293-8.

45. Bottius E, Guanzirolli A, Trape JF, Regier C, Konate L, Druilhe P. Malaria: even more chronic in nature than previously thought; evidence for subpatent parasitaemia detectable by the polymerase chain reaction. Trans $\mathrm{R}$ Soc Trop Med Hyg. 1996;90:15-9.

46. de Andrade AL, Martelli CM, Oliveira RM, Arias JR, Zicker F, Pang L. High prevalence of asymptomatic malaria in gold mining areas in Brazil. Clin Infect Dis. 1995;20:475.

47. Eke RA, Chigbu LN, Nwachukwu W. High prevalence of asymptomatic Plasmodium infection in a suburb of Aba Town, Nigeria. Ann Afr Med. 2006;5:42-5.

48. Dal-Bianco MP, Koster KB, Kombila UD, Kun JF, Grobusch MP, Ngoma GM, et al. High prevalence of asymptomatic Plasmodium falciparum infection in Gabonese adults. Am J Trop Med Hyg. 2007;77:939-42.

49. Sattabongkot J, Maneechai N, Phunkitchar V, Eikarat N, Khuntirat B, Sirichaisinthop J, et al. Comparison of artificial membrane feeding with direct skin feeding to estimate the infectiousness of Plasmodium vivax gametocyte carriers to mosquitoes. Am J Trop Med Hyg. 2003;69:529-35.

50. Bharti AR, Chuquiyauri R, Brouwer KC, Stancil J, Lin J, Llanos-Cuentas A, et al. Experimental infection of the neotropical malaria vector Anopheles darlingi by human patient-derived Plasmodium vivax in the Peruvian Amazon. Am J Trop Med Hyg. 2006;75:610-6.
Ready to submit your research? Choose BMC and benefit from:

- fast, convenient online submission

- thorough peer review by experienced researchers in your field

- rapid publication on acceptance

- support for research data, including large and complex data types

- gold Open Access which fosters wider collaboration and increased citations

- maximum visibility for your research: over 100M website views per year

At BMC, research is always in progress.

Learn more biomedcentral.com/submissions 